\title{
Echinocystic acid ameliorates hyperhomocysteinemia-induced vascular endothelial cell injury through regulating NF-кB and CYP1A1
}

\author{
CHUAN-FENG HUANG ${ }^{1,2}$, WEI-NA WANG ${ }^{1,2}$, CHENG-CAO SUN $^{1}$, \\ YU-QING WANG ${ }^{2}$, LING LI $^{1,2}$, YIN LI $^{2}$ and DE-JIA LI ${ }^{1}$ \\ ${ }^{1}$ Department of Occupational and Environmental Health, School of Public Health, Wuhan University, Wuhan, Hubei 430071;
${ }^{2}$ Department of Pharmacology, Basic Medical School, Nanyang Medical College, Nanyang, Henan 473003, P.R. China
}

Received April 13,2016; Accepted April 28, 2017

DOI: $10.3892 /$ etm.2017.5097

\begin{abstract}
The present study investigated the role of echinocystic acid (EA) on the expression of nuclear factor (NF)- $\mathrm{\kappa B}$ and cytochrome P450 1A1 (CYP1A1), and aortic morphology, in a rat model of hyperhomocysteinemia (Hhcy). A total of 50 Sprague Dawley rats were randomly divided into five groups as follows: Normal control $(\mathrm{NC})$, model control (MC), vitamin control (VC; folic acid $1 \mathrm{mg} / \mathrm{kg}+$ vitamin B2 $2 \mathrm{mg} / \mathrm{kg}+$ vitamin B12 10u g/kg), EA1 (20 mg/kg EA) and EA2 (40 mg/kg EA). Plasma homocysteine (Hcy) levels were determined via high performance liquid chromatography, and the morphology of the aorta was investigated using hematoxylin and eosin staining. Furthermore, aortic mRNA and protein levels of NF- $\kappa \mathrm{B}$ and CYP1A1 were measured using reverse transcription-quantitative polymerase chain reaction analysis and western blotting, respectively. Plasma Hcy levels, and aortic mRNA and protein levels of NF- $\kappa B$ and CYP1A1, were significantly lower in the EA-treated group compared with the MC group (all $\mathrm{P}<0.05$ ). However, the aortic morphology remained normal, including the endothelial cells of the inner layer, and smooth muscle cells of the media layer and adventitia. In conclusion, the results of the present study indicate that EA has a protective role on vascular endothelial cells in Hhcy through decreasing plasma Hcy, and thus NF- $\mathrm{KB}$ and CYP1A1 expression.
\end{abstract}

\section{Introduction}

Homocysteine (Hcy) is an intermediate product of methionine demethylation. Hyperhomocysteinemia (Hhcy) has been

Correspondence to: Dr De-Jia Li, Department of Occupational and Environmental Health, School of Public Health, Wuhan University, 115 Donghu Road, Wuhan, Hubei 430071, P.R. China

E-mail: lidejiajia@sina.com

Key words: echinocystic acid, hyperhomocysteinemia, nuclear factor $\kappa \mathrm{B}$, cytochrome P450 1A1, vascular endothelial cells associated with an increased incidence of cardiovascular disease, including peripheral vascular disease, and has been reported to be a novel independent risk factor for atherosclerosis (AS) (1). The underlying molecular mechanism by which Hhcy increases the risk of these diseases remains unknown. The proposed mechanisms include affecting the expression of various factors that regulate vascular endothelial cell functions and processes, including oxidative stress, inflammation and immune responses (1-3). Hcy can increase oxidative stress, which subsequently leads to the activation of the nuclear factor (NF) $\kappa \mathrm{B}$ signaling pathway and inflammation (4). This results in endothelial dysfunction and promotes the development of AS (5). The combined usage of vitamin B6, Vitamin B12 and folic acid has been demonstrated to significantly decrease plasma levels of Hcy (6); however, the mechanism underlying this effect remains unclear.

Two traditional Chinese medicines, produced from Codonopsis lanceolate and Gleditsia sinensis Lam, are widely used in the treatment of various inflammation-associated diseases, and have been demonstrated to exhibit multiple effects, including antihaemolysis, antitumorigenesis, anti-inflammation, anti-infection and lowering cholesterol level $(7,8)$. Echinocystic acid (EA) is a triterpenoid of the $\beta$-amyrin family, which is primarily derived from the rhizome of $C$. lanceolate and the fruits of $G$. sinensis Lam (9). Previous studies have revealed that EA exhibits anti-inflammatory effects on lysophosphatidic acid-induced alveolar macrophages and pneumonia in mice through regulating the $\mathrm{NF}-\kappa \mathrm{B}$ and mitogen-activated protein kinase signaling pathways (10-12). In addition, EA has an antiapoptotic effect, which allows EA to exert a protective effective against the ischemia-reperfusion injury of cardiomyocytes (13).

Previous studies have demonstrated that cytochrome P450 1A1 (CYP1A1) is an important enzyme in drug metabolism, lipid and steroid synthesis, and the metabolism of toxic molecules (14-18). CYP1A1 metabolizes endogenous arachidonic acid into hydroxyeicosatetraenoic acid, which has detrimental roles in cardiovascular disease, such as affecting the metabolism of arachidonic acid (19). Thus, CYP1A1 may serve a role in Hcy metabolism (20). CYP1A1 also serves an antioxidant/protective role against toxicity in the aorta (21). 
The present study investigated whether CYP1A serves a role in the Hcy-induced alteration of the aorta, such as the effect of CYP1A on the level of Hcy and arterial injury, and examined the effect of EA on the morphology of the aorta and serum Hcy levels, in addition to the potential molecular mechanisms underlying these effects.

\section{Materials and methods}

Animals. A total of 50 male specific pathogen-free Sprague Dawley rats (5 weeks old, 180-200 g) were housed at the animal facility of Wuhan University Institute of Comparative Medicine (Wuhan, China). The rats were kept under conditions of $19-25^{\circ} \mathrm{C}$ with a relative humidity of $40-60 \%$ and light/dark cycle of $12 \mathrm{~h}$. The present study was approved by the Animal Care Committee of Wuhan University.

Reagents. EA monomer was obtained from Nanjing Chunqiu Biotechnology Co. (Nanjing, China; cat. no. AB2013A0001) with a purity of $99.5 \%$. The chemical structure of EA is illustrated in Fig. 1. Prior to experiments, $0.3 \%$ sodium carboxymethylcellulose (cat. no. F20012203; Sinopharm Chemical Reagent Co., Ltd, Shanghai, China) was added to the EA powder to produce a solution of $4 \mathrm{mg} / \mathrm{ml}$ EA. High L-methionine diet was produced by adding 3\% L-methionine (Aladdin Reagent Co. Ltd., Shanghai, China; batch no. 96934001) to chow diet (purchased from Wuhan University). All diet was stored in $4^{\circ} \mathrm{C}$ prior to use. Reagents for RNA isolation, reverse transcription (RT) and quantitative polymerase chain reaction (qPCR) were obtained from Takara Biotechnology Co., Ltd. (Dalian, China), including TRIzol (cat. no. B4102-1), PrimeScript ${ }^{\mathrm{TM}}$ RT reagent kit with gDNA Eraser (cat. no. AK2501) and SYBR ${ }^{\circledR}$ Premix Ex Taq ${ }^{\mathrm{TM}}$ (cat. no. AK4403). For western blotting, anti-NF- $\kappa$ B (sc-372, 1:1,000), anti-CYP1A1 (sc-20772, 1:1,000) and anti- $\beta$ - $\alpha$ ctin (sc-130065, 1:1,000) antibodies were obtained from Santa Cruz Biotechnology, Inc. (Dallas, TX, USA). Secondary antibody horseradish peroxidase-labeled goat anti-rat IgG (cat. no. GB23302) was purchased from Wuhan Servicebio Technology Co., Ltd. (Wuhan, China) and Pierce ECL Western Blotting Substrate was obtained from Thermo Fisher Scientific, Inc. (Waltham, MA, USA). qPCR primers were synthesized by Shanghai Shenggong Biology Engineering Technology Service, Ltd. (Shanghai, China). The sequences of the primers used for RT and qPCR were as follows: NF- $\mathrm{BB}$ forward, 3'-GCTCCTTTTCTCAAGCCGATGT-5' and reverse, 3'-CGTAGGTCCTTTTGCGTTTTTC-5' (product size, 220 bp); CYP1A1 forward, 3'-TCAGGACAGGAGGCTGGA CGA-5' and reverse, 3'-GGATGGTGAATGGGACAAAGG AT-5' (product size, $293 \mathrm{bp}$ ); and $\beta$-actin forward, 3'-TGCTAT GTTGCCCTAGACTTCG-5' and reverse, 3'-GTTGGCATA GAGGTCTTTACGG-5' (product size, 240 bp).

Groups and establishment of the Hhcy model. Animals in all groups were fed on a chow diet for 1 week prior to the experiments. Subsequently, a high L-methionine diet was used to induce Hhcy in the rat as previously described (22-24). Rats were then randomly divided into the following groups ( $n=10$ /group) for the 8-week-long experiment: Normal control group (NC; chow diet, daily gastric gavage with normal saline); model control group (MC; high L-methionine diet, daily

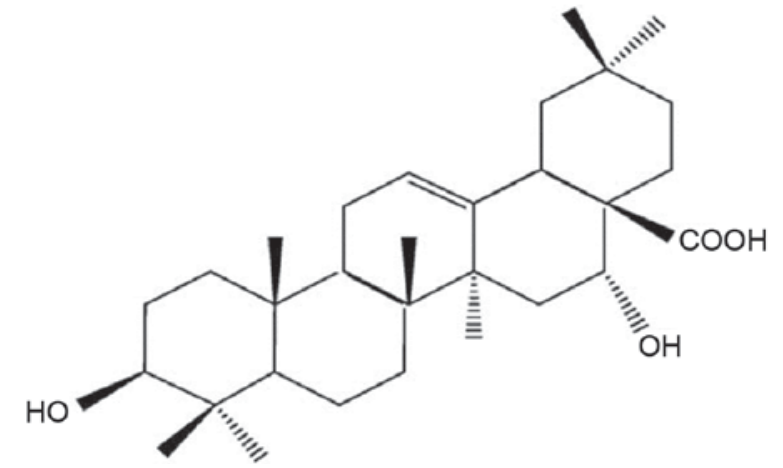

Figure 1. Chemical structure of echinocystic acid.

gastric gavage with normal saline); vitamin control group (VC; high L-methionine diet, daily gastric gavage with folic acid $1 \mathrm{mg} / \mathrm{kg}$ + vitamin B2 mg/kg + vitamin B12 $10 \mu \mathrm{g} / \mathrm{kg}$, Aladdin Reagent Co. Ltd.); EA low dose group (EA1; high L-methionine diet, daily gastric gavage with $20 \mathrm{mg} / \mathrm{kg} \mathrm{EA}$ ); and EA high dose group (EA2; high L-methionine diet, daily gastric gavage with $40 \mathrm{mg} / \mathrm{kg}$ EA). Body weight was measured every week in order to adjust the dose of EA and vitamins accordingly.

Histology. Cardiac tissue samples were fixed at room temperature with $10 \%$ neutral formalin for $5 \mathrm{~h}$. After dehydration with an increasing series of graded ethanol solutions, specimens were collected, embedded in paraffin at $\sim 60^{\circ} \mathrm{C}$ for $5-6 \mathrm{~h}$ and then sectioned (5- $\mu \mathrm{m}$-thick). The sections were stained with hematoxylin and eosin $(\mathrm{H} \& \mathrm{E})$ at $70^{\circ} \mathrm{C}$ for $30 \mathrm{~min}$. Histological changes were then observed through a light microscope. Images of five visual fields were captured for each sample, and the average of thickness of the media and intima were calculated from five points in each images.

Determination of plasma Hcy levels. Animals underwent fasting for $12 \mathrm{~h}$ and were weighed, then 3-5 ml whole blood was drawn from the left ventricle under anesthesia. The animals were sacrificed and cardiac tissue samples were harvested. Heparin was used as an anticoagulant after the blood was drawn (10 IU heparin/1 ml blood). High performance liquid chromatography was used to measure plasma Hcy levels (25).

$R T-q P C R$ analysis. Total RNA was extracted from the samples using TRIzol according to the manufacturer's protocol. cDNA was synthesized using $1 \mu \mathrm{g}$ of total RNA as the template and specific primers with the PrimeScript ${ }^{\mathrm{TM}} \mathrm{RT}$ reagent kit with gDNA Eraser according to the manufacturer's protocol. qPCR was performed using the $\mathrm{SYBR}^{\circledR}$ Premix Ex Taq ${ }^{\mathrm{TM}}$ according to the manufacturer's protocol $\left(95^{\circ} \mathrm{C}\right.$ for $30 \mathrm{sec}$, then $95^{\circ} \mathrm{C}$ for $5 \mathrm{sec}$ and $60^{\circ} \mathrm{C}$ for $34 \mathrm{sec}, 30$ cycles). The PCR products and the concentration of target gene and reference gene amplification products were obtained by standard curve analysis software in the computer and calculated using the $2^{-\Delta \Delta C q}$ method (26). The expression level of NF- $\kappa \mathrm{B}$ and CYP1A1 genes were normalized to the $\beta$-actin.

Western blotting. Total protein was extracted from the aorta using radioimmunoprecipitation assay buffer [50 $\mathrm{mM}$ Tris 

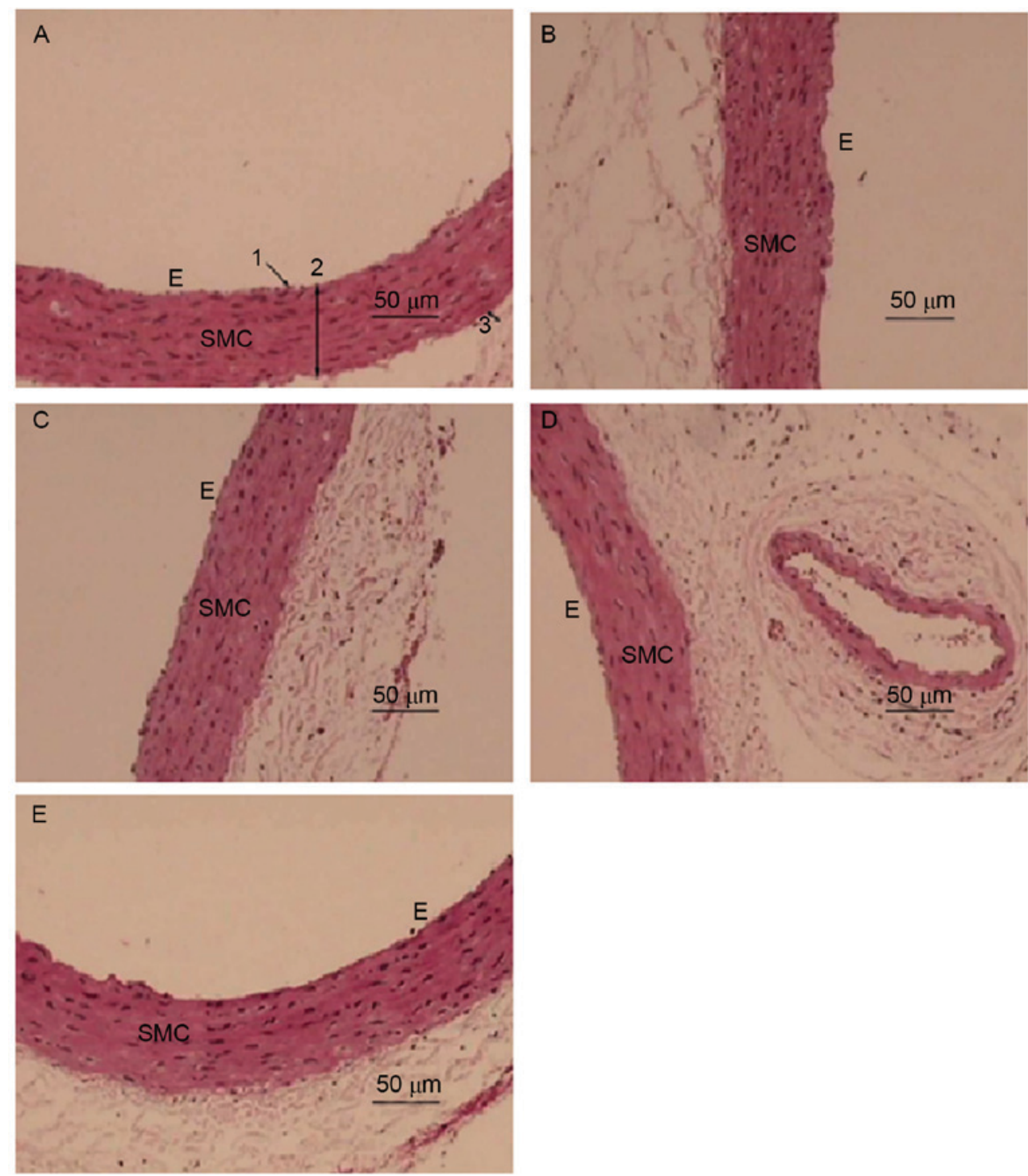

Figure 2. EA attenuates hyperhomocysteinemia-induced changes in aortic morphology. Representative hematoxylin and eosin stained sections of aortic tissue from the (A) negative control, (B) model control, (C) vitamin control, (D) EA1 and (E) EA2 groups. 1, endothelial layer; 2, intima-media layer; 3, adventitia; SMC, smooth muscle cells; E, endothelial cells; EA, echinocystic acid.

(pH 7.4), $150 \mathrm{mM} \mathrm{NaCl}, 1 \%$ Triton X-100, $1 \%$ sodium deoxycholate, $0.1 \%$ SDS, $2 \mathrm{mM}$ sodium pyrophosphate, $25 \mathrm{mM}$ $\beta$-glycerophosphate, $1 \mathrm{mMEDTA}, 1 \mathrm{mMNa}_{3} \mathrm{VO}_{4}$ and $0.5 \mu \mathrm{g} / \mathrm{ml}$ leupeptin]. Protein concentrations were determined by BCA protein assay. Samples were heated at $100^{\circ} \mathrm{C}$ for $10 \mathrm{~min}$ to denature after the addition of $5 \mathrm{X}$ SDS-PAGE sample buffers. Proteins $(50 \mu \mathrm{g} / \mathrm{lane})$ were resolved by $10 \%$ SDS-PAGE gel and transferred to a polyvinylidene difluoride membrane. After blocking with 5\% bovine serum albumin (Shanghai Liansuo Biological Technology Co. Ltd., Shanghai, China) at $37^{\circ} \mathrm{C}$ for $1 \mathrm{~h}$, the membranes were incubated with primary antibodies anti-NF- $\mathrm{B}$ p 65 , anti-CYP1A1 $(1: 1,000)$ and anti- $\beta$-actin $(1: 5,000)$ at $4^{\circ} \mathrm{C}$ overnight. This was followed by a second incubation step with horseradish peroxidase-conjugated goat anti-rabbit IgG secondary antibodies $(1: 12,000)$ at $37^{\circ} \mathrm{C}$ for $1 \mathrm{~h}$. Protein bands were then visualized using the Pierce ECL Western Blotting Substrate according to the manufacturer's protocol. Quantification of band density was performed using Quantity One software (version 4.4.0; Bio-Rad Laboratories, Inc., Hercules, CA, USA).
Statistics. Data are presented as the mean \pm standard deviation of three independent experiments. All data were analyzed using SPSS software (version 13.0; SPSS, Inc., Chicago, IL, USA). The data from experiments with multiple groups were analyzed using one-way analysis of variance and post hoc analysis (Fisher's least significant difference or Student-Newman-Keuls method). Data were compared between groups by least significance difference combined with Tamhane's test. $\mathrm{P}<0.05$ was considered to indicate a statistically significant difference.

\section{Results}

EA attenuates Hhcy-induced changes in aortic morphology. H\&E staining was employed to examine the effect of EA on the morphology of the aorta in Hhcy (Fig. 2). The aorta from the NC group exhibited an intact endothelial cell lining parallel to the adventitia (Fig. 2A). The aortic wall had an equal thickness throughout the entire section, was lined with smooth muscle cells (SMCs) and possessed endothelial cells 
Table I. Media and intima thickness in the thoracic aorta.

\begin{tabular}{lc}
\hline Group & Media and intima thickness $(\mu \mathrm{m})$ \\
\hline NC & $66.3 \pm 1.4$ \\
MC & $76.5 \pm 2.7^{\mathrm{a}, \mathrm{b}}$ \\
VC & $69.1 \pm 1.8$ \\
EA1 & $66.2 \pm 2.2^{\mathrm{c}}$ \\
EA2 & $67.5 \pm 1.6^{\mathrm{c}}$
\end{tabular}

$\mathrm{NC}$, negative control; MC, model control; VC, vitamin control; EA, echinocystic acid. ${ }^{a} \mathrm{P}<0.05$ vs. the $\mathrm{NC}$ group; ${ }^{\text {}} \mathrm{P}<0.05$ vs. the $\mathrm{VC}$ group; ${ }^{\mathrm{P}}<0.05$ vs. the $\mathrm{MC}$ group.

with a normal morphology (Fig. 2A). By contrast, the inner membrane or tunica intima of the aorta from the MC group was thickened with abundant SMCs lining (Fig. 2B; Table I). The structure of the aorta media layer became irregular and thinner in the MC group compared with that of the control group, with smooth muscle fiber separation and fracture, characteristic aortic changes of Hhcy, indicating the successful establishment of a Hhcy model. The inner membrane of the aorta from the EA1 group still exhibited a slightly disrupted media layer structure (Fig. 2D). However, as the dose of EA increased in the EA2 group the inner layer of the aortic lining exhibited a normal integrity with only slight thickening and a regular arrangement of SMCs in the media layer (Fig. 2E), similar to the aorta from the VC group (Fig. 2C).

EA decreases plasma Hcy levels in Hhcy. The effect of EA on plasma Hcy levels was investigated (Fig. 3). Compared with the NC group, the Hcy levels of rats in the MC, VC, EA1 and EA2 groups were significantly increased (all $\mathrm{P}<0.05$ ). Serum Hcy levels in the EA1 were significantly higher compared with that of the VC group $(\mathrm{P}<0.05)$, suggesting a higher efficiency of folic acid, vitamin B2 and vitamin B12 in lowing plasma Hcy. However, the effect of EA in lowing plasma Hcy levels was dose-dependent, since the Hcy level of the EA2 group was significantly lower compared with that of the EA1 group $(\mathrm{P}<0.05)$. There was no significant difference in Hcy levels between the VC and EA2 groups, indicating a similar Hcy-lowering effect of high dose EA and vitamins.

EA decreases the $m R N A$ and protein expression of $N F-\kappa B$ and CYPIA1 in the aorta in Hhcy. A previous study identified that EA had an anti-inflammatory effect through regulating $\mathrm{NF}-\kappa \mathrm{B}(8)$. CYP1A1 is an important enzyme in catalyzing the metabolism of drugs and toxic molecules, and lipid and steroid synthesis (13). The present study investigated the influence of EA on the expression of NF- $\kappa \mathrm{B}$ and CYP1A1 mRNA using RT-qPCR (Fig. 4). This demonstrated that NF- $\kappa \mathrm{B}$ and CYP1A1 mRNA levels in the MC group were significantly higher compared with those in the NC group (both $\mathrm{P}<0.05$ ). The VC, EA1 and EA2 groups had significantly decreased $\mathrm{NF}-\kappa \mathrm{B}$ and CYP1A1 mRNA expression levels compared with the MC group (all $\mathrm{P}<0.05$ ). Compared with the VC group, the EA1 and EA2 groups had significantly decreased CYP1A1 mRNA expression $(\mathrm{P}<0.05)$. By contrast, only the EA2 group

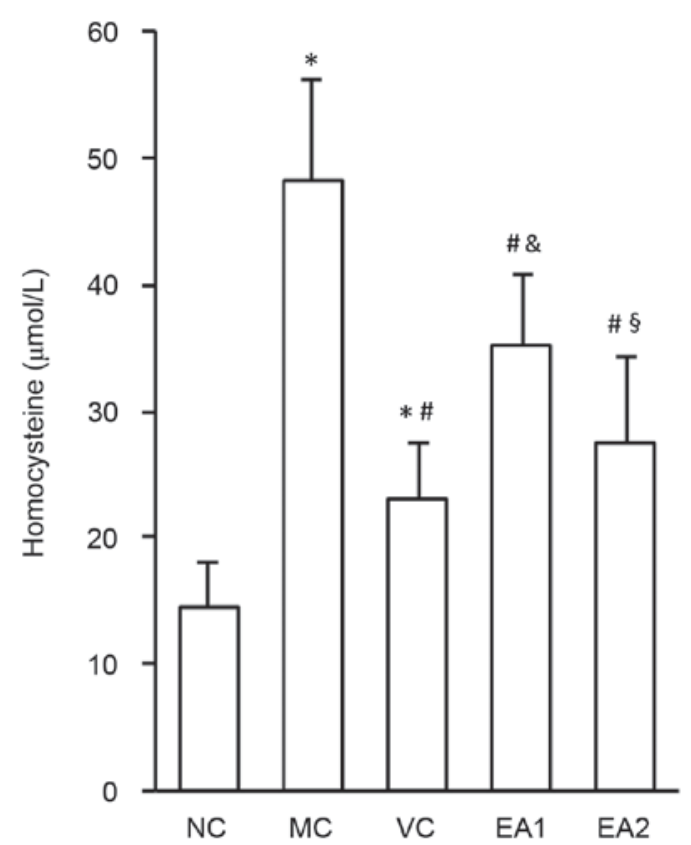

Figure 3. EA decreases plasma homocysteine levels in hyperhomocysteinemia. " $\mathrm{P}<0.05$ vs. the NC group; ${ }^{\#} \mathrm{P}<0.05$ vs. the $\mathrm{MC}$ group; ${ }^{\circledR} \mathrm{P}<0.05$ vs. the VC group; ${ }^{\S} \mathrm{P}<0.05$ vs. the EA1 group. NC, negative control; MC, model control; VC, vitamin control; EA, echinocystic acid.

had a significant decrease in NF- $\mathrm{NB}$ mRNA compared with the VC group $(\mathrm{P}<0.05)$.

The protein expression of NF- $\mathrm{B}$ and CYP1A1 was investigated in the Hhcy model with and without EA treatment (Fig. 5). Similar to the mRNA levels, NF- $\kappa$ B and CYP1A1 protein levels were significantly higher in the MC group compared with the $\mathrm{NC}$ group $(\mathrm{P}<0.05)$. The VC, EA1 and EA2 groups exhibited significantly lower $\mathrm{NF}-\kappa \mathrm{B}$ and CYP1A1 protein levels compared with the MC group $(\mathrm{P}<0.05)$. EA was significantly more effective at lowering NF- $\kappa \mathrm{B}$ and CYP1A1 protein levels compared with the vitamin treatment (EA1 vs. the VC group; EA2 vs. the VC group; both $\mathrm{P}<0.05$ ). This effect of EA was dose-dependent, with the EA2 group exhibiting significantly lower levels of $\mathrm{NF}-\kappa \mathrm{B}$ and CYP1A1 protein compared with the EA1 group $(\mathrm{P}<0.05)$. In addition, $\mathrm{NF}-\kappa \mathrm{B}$ protein levels in the EA2 group were normalized to the $\mathrm{NC}$ group level.

\section{Discussion}

Hcy is one of the intermediates produced by demethylation during methionine metabolism and $1 \%$ of Hcy exists freely in the circulation. The remaining $99 \%$ of Hcy combines with different proteins, primarily albumin, in vivo (1). Hhcy refers to a condition of increased plasma Hcy level, reaching a level that is associated with an increased risk of cardiovascular disease, including ischemic heart disease, stroke and peripheral vascular disease (1-3). Hhcy is determined by various factors, including genetics, nutrition, medication, disease status, smoking and age. Several large-scale clinical and epidemiological studies have revealed that Hhcy is an independent risk factor for AS (27). However, the pathogenesis and underlying mechanism by which Hhcy increases the risk of AS remains unclear. Proposed mechanisms include oxidative 
A

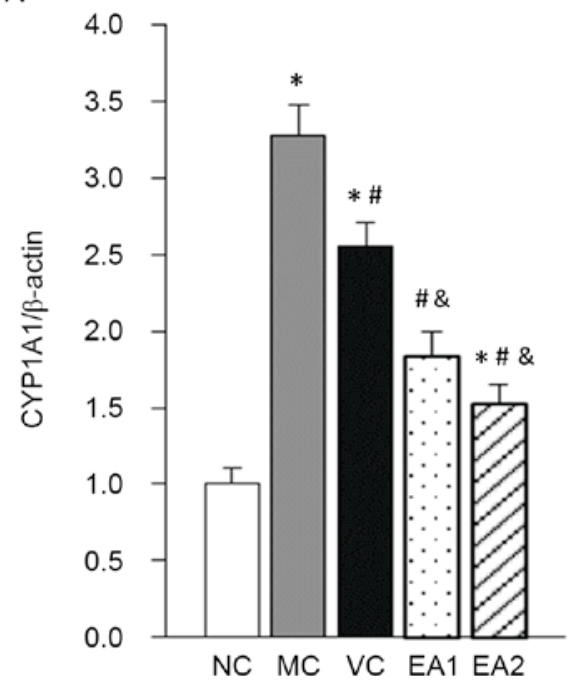

B

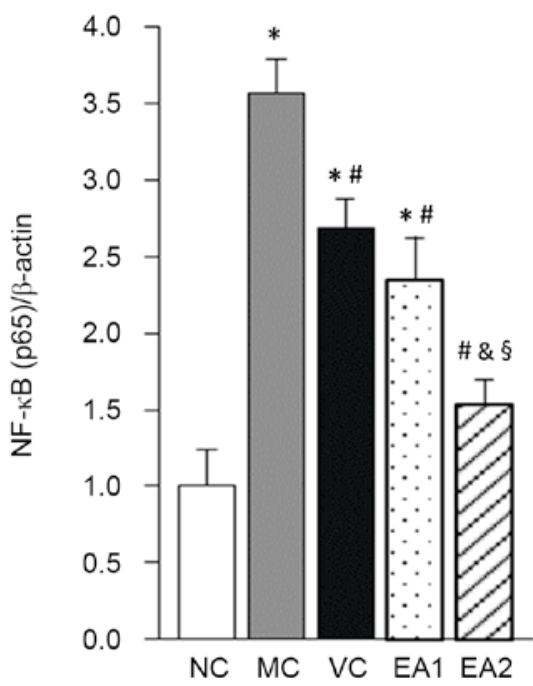

Figure 4. EA decreases the mRNA expression of NF- $\mathrm{B}$ and CYP1A1 in the aorta in hyperhomocysteinemia. mRNA expression of (A) CYP1A1 and (B) NF- $\mathrm{kB}$ was measured via reverse transcription-quantitative polymerase chain reaction analysis. ${ }^{*} \mathrm{P}<0.05$ vs. the $\mathrm{NC}$ group; ${ }^{\#} \mathrm{P}<0.05 \mathrm{vs}$. the $\mathrm{MC}$ group; ${ }^{\circledR} \mathrm{P}<0.05$ vs. the VC group; ${ }^{\S} \mathrm{P}<0.05$ vs. the EA1 group. NC, negative control; MC, model control; VC, vitamin control; EA, echinocystic acid; NF- $\kappa \mathrm{B}$, nuclear factor $\kappa \mathrm{B}$; CYP1A1, cytochrome P450 1A1.

NC MC VC EA1 EA2
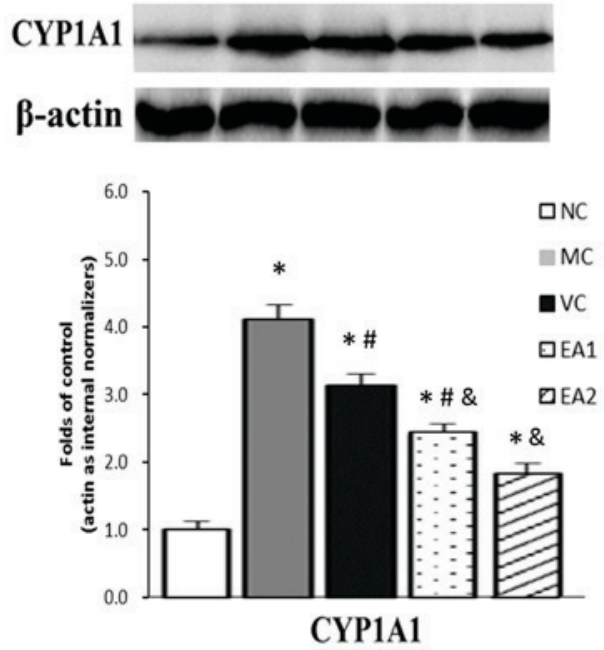

NC MC VC EA1 EA2
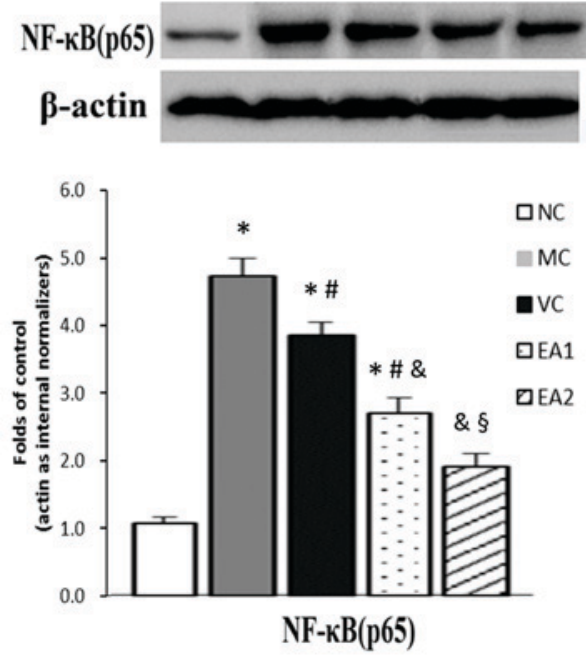

Figure 5. EA decreases the protein expression of CYP1A1 and NF- $\kappa \mathrm{B}$ in the aorta in hyperhomocysteinemia. Protein expression of $\mathrm{CYP} 1 \mathrm{~A} 1$ and $\mathrm{NF}-\kappa \mathrm{B}$ was measured via western blotting and densitometry. ${ }^{*} \mathrm{P}<0.05$ vs. the $\mathrm{NC}$ group; ${ }^{\#} \mathrm{P}<0.05$ vs. the MC group; ${ }^{\circledR} \mathrm{P}<0.05$ vs. the VC group; ${ }^{\S} \mathrm{P}<0.05$ vs. the EA1 group. $\mathrm{NC}$, negative control; MC, model control; VC, vitamin control; EA, echinocystic acid; NF- $\kappa \mathrm{B}$, nuclear factor $\kappa \mathrm{B}$; CYP1A1, cytochrome P450 1A1.

stress, inflammation and immune responses, which directly influence vascular endothelial cell function (28). Therefore, agents that lower Hcy are potential treatments to prevent the development of AS.

AS is broadly regarded as a process of chronic inflammation (29-31). NF- $\kappa \mathrm{B}$ is an important transcription factor in the regulation of the immune response and inflammation, which affect endothelial function. Endothelial dysfunction initiates the development of AS (32,33). Previous results have demonstrated that Hcy can increase oxidative stress (4), leading to the subsequent activation of the NF- $\kappa \mathrm{B}$ signaling pathway, which induces inflammation. This causes endothelial dysfunction and promotes the development of AS (2). Therefore, regulating the $\mathrm{NF}-\kappa \mathrm{B}$ signaling pathway could inhibit inflammation and prevent the development of AS. CYP is a heme-containing monooxygenase superfamily. CYP family proteins serve a role in the oxidative metabolism of endogenous and exogenous molecules, which maintains cardiovascular hemostasis (34). CYP1A1 is highly expressed in vascular endothelial cells, and there are interactions between PAHs and CYP1A1 (35). The present results indicated that the expression levels of Hcy and CYP1A1 of Hhcy rats were increased, while Hcy level and CYP1A1 in EA group were decreased, suggesting that there may be some interaction between Hcy and CYP1A1, and EA could reduce the level of them. CYP1A1 metabolizes endogenous arachidonic acids, including hydroxyeicosatetraenoic 
acid, which serves a role in cardiovascular disease, renal disease, pulmonary sclerosis and anti-platelet activity (36). A previous study demonstrated that NF- $\kappa$ B directly regulates CYP1A1 activity together with a heavy metal ion, indicating that there is an association between NF- $\mathrm{B}$ and CYP1A1 (37).

The present study identified that plasma Hcy levels were increased in the Hhcy rat model, indicating successful model establishment. Hhcy was accompanied with vascular endothelial cell injury in this model. EA treatment could significantly reduce plasma Hcy levels, although it was not typically as effective as the vitamin treatment (vitamin B2, vitamin B12 and folic acid). Van Mil et al (38) reported that folic acid reduced levels of the proinflammatory chemokines monocyte chemoattractant protein 1 and interleukin 8 through decreasing plasma Hcy levels; however, the authors concluded that folic acid did not protect against AS development. The current study identified that EA significantly decreased NF- $\kappa$ B and CYP1A1 protein and mRNA levels in a dose-dependent manner. This indicates that EA has a protective effect on endothelial cells in Hhcy. In addition, EA decreased Hcy levels and had an antioxidant effect through decreasing NF- $\mathrm{B}$ and CYP1A1 expression. However, the underlying molecular mechanisms through which EA decreases Hcy, NF- $\mathrm{B}$ and CYP1A1 requires further investigation.

In conclusion, the results of the present study indicate that EA exerts a protective role on vascular endothelial cells in Hhcy. EA likely exerts this effect through decreasing plasma Hcy levels and thus NF- $\mathrm{BB}$ and CYP1A1 expression. Future studies should investigate the underlying molecular mechanisms of these effects.

\section{Acknowledgements}

The present study was supported by the Science and Technology Development Project of Nanyang City (grant no. 2011GG041).

\section{References}

1. Fowler B: Homocystein-an independent risk factor for cardiovascular and thrombotic diseases. Ther Umsch 62: 641-646, 2005.

2. Lentz SR: Mechanisms of homocysteine-indued atherothrombosis. Thromb Haemost 3: 1646-1654, 2005.

3. De Bree A, Verschuren WM, Kromhout D, Kluijtmans LA and Blom HJ: Homocysteine determinants and the evidence to what extent homocysteine determines the risk of coronary heart disease. Pharmacol Rev 54: 599-618, 2002.

4. Hidiroglou N, Gilani GS, Long L, Zhao X, Madere R, Cockell K, Belonge B, Ratnayake WM and Peace R: The influence of dietary vitamin $\mathrm{E}$, fat, and methionine on blood cholesterol profile, homocysteine levels, and oxidizability of low density lipoprotein in the gerbil. J Nutr Biochem 15: 730-740, 2004.

5. Lin CP, Chen YH, Chen JW, Leu HB, Liu TZ, Liu PL and Huang SL: Cholestin (Monascus purpureus rice) inhibits homocysteine-induced reactive oxygen species generation, nuclear factor-kappaB activation, and vascular cell adhesion molecule-1 expression in human aortic endothelial cells. J Biomed Sci 15 183-196, 2008

6. Remacha AF, Souto JC, Piñana JL, Sardà MP, Queraltó JM, Martí-Fabregas J, García-Moll X, Férnandez C, Rodriguez A and Cuesta J: Vitamin B12 deficiency, hyperhomocysteinemia and thrombosis: A case and control study. Int J Hematol 93: 458-464, 2011.

7. Deng YT, Kang WB, Zhao JN, Liu G and Zhao MG: Osteoprotective effect of echinocystic acid, a triterpone component from eclipta prostrata, in ovariectomy-induced osteoporotic rats. PLoS One 10: e0136572, 2015.
8. Xu LP, Wang $\mathrm{H}$ and Yuan Z: Triterpenoid saponins with anti-inflammatory activity from Codonopsis lanceolata. Planta Med 74: 1412-1425, 2008.

9. Joh EH, Gu W and Kim DH: Echinocystic acid ameliorates lung inflammation in mice and alveolar macrophages by inhibiting the binding of LPS to TLR4 in NF- $\kappa \mathrm{B}$ and MAPK pathways. Biochem Pharmacol 84: 331-340, 2012.

10. Joh EH, Gu W and Kim DH: Echinocystic acid ameliorates lung inflammation in mice and alveolar macrophages by inhibiting the binding of LPS to TLR4 in NF-kB and MAPK pathways. Biochem Pharmacol 84: 331-340, 2012.

11. Joh EH, Jeong JJ and Kim DH: Inhibitory effect of echinocystic acid on 12-O-tetradecanoylphorbol-13-acetate-induced dermatitis in mice. Arch Pharm Res 37: 225-231, 2014.

12. Ryu S, Shin JS, Jung JY, Cho YW, Kim SJ, Jang DS and Lee KT: Echinocystic acid isolated from Eclipta prostrata suppresses lipopolysaccharide-induced iNOS, TNF- $\alpha$ and IL- 6 expressions via NF- $\kappa$ B inactivation in RAW 264.7 macrophages. Planta Med 79: 1031-1037, 2013.

13. Wu J, Li J, Zhu Z, Li J, Huang G, Tang Y and Gao X: Protective effects of echinocystic acid isolated from Gleditsia sinensis Lam. against acute myocardial ischemia. Fitoterapia 81: 8-10, 2010.

14. Zou JG, Ma YT, Xie X, Yang YN, Pan S, Adi D, Liu F and Chen BD: Erratum to: The association between CYP1A1 genetic polymorphisms and coronary artery disease in the Uygur and Han of China. Lipids Health Dis 14: 118, 2015.

15. Wang XL, Greco M, Sim AS, Duarte N, Wang J and Wilcken DE: Effect of CYP1A1 MspI polymorphism on cigarette smoking related coronary artery disease and diabetes. Atherosclerosis 162: 391-397, 2002.

16. Jarvis MD, Palmer BR, Pilbrow AP, Ellis KL, Frampton CM, Skelton L, Doughty RN, Whalley GA, Ellis CJ, Yandle TG, et al: CYP1A1 MSPI (T6235C) gene polymorphism is associated with mortality in acute coronary syndrome patients. Clin Exp Pharmacol Physiol 37: 193-198, 2010.

17. Achour B, Barber J and Rostami-Hodjegan A: Expression of hepatic drug-metabolizing cytochrome P450 enzymes and their intercorrelations: A meta-analysis. Drug Metab Dispos 42: 1349-1356, 2014

18. Morel Y and Barouki R: Down-regulation of cytochrome P450 $1 \mathrm{~A} 1$ gene promoter by oxidative stress. Critical contribution of nuclear factor 1. J Biol Chem 273: 26969-26976, 1998.

19. Chu ZM, Croft KD, Kingsbury DA, Falck JR, Reddy KM and Beilin LJ: Cytochrome P450 metabolites of arachidonic acid may be important mediators in angiotensin II-induced vasoconstriction in the rat mesentery in vivo. Clin Sci (Lond) 98: 277-282, 2000.

20. Zhou B, He S, Wang XI, Zhen X, Su X and Tan W: Metabolism of arachidonic acid by the cytochrome $\mathrm{P} 450$ enzyme in patients with chronic Keshan disease and dilated cardiomyopathy. Biomed Rep 4: 251-255, 2016.

21. Uno S, Sakurai K, Nebert DW and Makishima M: Protective role of cytochrome P450 1A1 (CYP1A1) against benzo[a] pyrene-induced toxicity in mouse aorta. Toxicology 316: 34-42, 2014.

22. Zhang R, Ma J, Xia M, Zhu H and Ling W: Mild hyperhomocysteinemia induced by feeding rats diets rich in methionine or deficient in folate promotes early atherosclerotic inflammatory processes. J Nutr 134: 825-830, 2014.

23. Song S, Kertowidjojo E, Ojaimi C, Martin-Fernandez B, Kandhi S, Wolin M and Hintze TH: Long-term methionine-diet induced mild hyperhomocysteinemia associated cardiac metabolic dysfunction in multiparous rats. Physiol Rep 3: pii: e12292, 2015.

24. da Cunha AA, Ferreira AG, da Cunha MJ, Pederzolli CD, Becker DL, Coelho JG, Dutra-Filho CS and Wyse AT: Chronic hyperhomocysteinemia induces oxidative damage in the rat lung. Mol Cell Biochem 358: 153-160, 2011.

25. Pfeiffer CM, Huff DL and Gunter EM: Rapid and accurate HPLC assay for plasma total homocysteine and cysteine in a clinical laboratory setting. Clin Chem 45: 290-292, 1999.

26. Livak KJ and Schmittgen TD: Analysis of relative gene expression data using real-time quantitative PCR and the2(-Delta Delta C(T)) method. Methods 25: 402-408, 2001.

27. Tamadon MR, Jamshidi L, Soliemani A, Ghorbani R, Malek F and Malek M: Effect of different doses of folic acid on serum homocysteine level in patients on hemodialysis. Iran J Kidney Dis 5: 93-96, 2011.

28. Yang RX, Huang SY, Yan FF, Lu XT, Xing YF, Liu Y, Liu YF and Zhao YX: Danshensu protects vascular endothelia in a rat model of hyperhomocysteinemia. Acta Pharmacol Sin 31: 1395-1400, 2010. 
29. Ross R: Atherosclerosis-an inflammatory diseas. N Engl J Med 340: 115-126, 1999.

30. Berliner JA, Navab M, Fogelman AM, Frank JS, Demer LL, Edwards PA, Watson AD and Lusis AJ: Atherosclerosis: Basic mechanisms. Oxidation, inflammation, and genetics. Circulation 91: 2488-2496, 1995.

31. Hossain GS, van Thienen JV, Werstuck GH, Zhou J, Sood SK Dickhout JG, de Koning AB, Tang D, Wu D, Falk E, et al: TDAG51 is induced by homocysteine, promotes detachment-mediated programmed cell death, and contributes to the cevelopment of atherosclerosis in hyperhomocysteinemia. J Biol Chem 278: 30317-30327, 2003.

32. Baird WM, Hooven LA and Mahadevan B: Carcinogenic polycyclic aromatic hydrocarbon-DNA adducts and mechanism of action. Environ Mol Mutagen 45: 106-114, 2005.

33. Hockley SL, Arlt VM, Brewer D, Te Poele R, Workman P, Giddings I and Phillips DH: AHR- and DNA-damage-mediated gene expression responses induced by benzo(a)pyrene in human cell lines. Chem Res Toxicol 20: 1797-1810, 2007.
34. Au-Yeung KK, Woo CW, Sung FL, Yip JC, Siow YL and O K: Hyperhomocysteinemia activities nuclear factor-kappaB in endothelial cells via oxidative stresss. Circ Res 94: 28-36, 2004.

35. Gao M, Li Y, Xue X, Long J, Chen L, Shah W and Kong Y: Impact of AhR, CYP1A1 and GSTM1 Genetic Polymorphisms on TP53 R273G Mutations in Individuals Exposed to Polycyclic Aromatic Hydrocarbons. Asian Pac J Cancer Prev 15: 2699-2705, 2014.

36. Demirdöğen BC, Adali AÇ, Bek S, Demirkaya Ş and Adali O: Cytochrome P4501A1 genotypes and smoking- and hypertension-related ischemic stoke risk. Hum Exp Toxicol 32: 483-491, 2013.

37. Zordoky BN and El-Kadi AO: Role of NF-kappaB in the regulation of cytochrome P450 enzymes. Curr Drug Metab 10: 164-178, 2009.

38. van Mil NH, Oosterbaan AM and Steegers-Theunissen RP: Teratogenicity and underlying mechanisms of homocysteine in animal models: A review. Reprod Toxicol 30: 520-531, 2010. 